УДК 316.485 .6

$10.17213 / 2075-2067-2020-6-62-68$

\title{
ОБЩЕСТВЕННЫЙ КОНТРОЛЬ КАК МЕХАНИЗМ ВОЗДЕЙСТВИЯ НА ВЛАСТЬ В СОЦИОЛОГИЧЕСКОМ ДИСКУРСЕ
}

\author{
(C) 2020 г. В. В. Кривопусков ${ }^{*}$, Р. Н. Первякова ${ }^{* *}$ \\ "АО «Главкосмос», г. Москва, Россия \\ "* Южный федеральный университет, г. Ростов-на-Дону, Россия
}

Целью исследования является анализ понятия «общественный контроль» в рамках современного сочиологического дискурса, выявление и характеристика ключевого исследовательского тренда его интерпретачии, характеризующегося междисииплинарным подходом.

Методологическую базу исследования составляют сравнительно-исторический и системно-структурные методы, позволяющие выявить основные тенденции эволючии анализа понятия «общественный контроль» в рамках современного социологического дискурса. Ключевые выводы относительно определения сущности понятия «общественный контроль» сделаны на основе применения методологии конфликтологической теории.

Результаты исследования. Проведенный анализ соииологического дискурса позволил определить его основной исследовательский тренд, связанный с выявлением в структуре общественного контроля принциипиально новых субъектно-объектных связей, выражающих его сущчнсть. В таком качестве рассматриваются отдельные граждане и их образования (в качестве субъектов) и публично-правовые властные структуры (объекты). В рамках данного подхода сформулировано авторское определение общественного контроля в качестве совокуиности общественных прочессов, осуществляемых с целью наблюдения за функционированием публично-правовых образований и их отдельных структур (органов государственной власти), проверки их деятельности на предмет соответствия принятым социальньмм нормам, общественным ожиданиям, а также с иелью применения к указанным структурам определенных мер воздействия для нивелирования возможных отклонений от указанных констант.

Перспективу исследования составляет анализ практического воплощения социальных процессов, определяющих сущность общественного контроля, в реальных условиях конкретно-исторической конъюнктуры.

Ключевые слова: общественный контроль; сочиологическая наука; демократическое правовое государство; общественное мнение; двустороннее взаимодействие; государственная власть.

\section{PUBLIC CONTROL AS A MECHANISM OF INFLUENCE ON THE GOVERNMENT IN THE SOCIOLOGICAL DISCOURSE}

\author{
(C) 2020 V. V. Krivopuskov*, R. N. Pervyakova** \\ "JSC «Glavkosmos», Moscow, Russia \\ *'Southern Federal University, Rostov-on-Don, Russia
}

The purpose of the research is to analyze the concept of «public control» in the framework of modern sociological discourse, identify and characterize the key research trend of its interpretation, characterized by an interdisciplinary approach. 
The methodological basis of the research is made up of comparative-historical and systemstructural methods that allow identifying the main trends in the evolution of the analysis of the concept of "public control» in the framework of modern sociological discourse. The key conclusions regarding the definition of the essence of the concept of «public control» are made on the basis of applying the methodology of conflict theory.

Research result. The analysis of the sociological discourse made it possible to determine its main research trend associated with the identification of fundamentally new subject-object relationships in the structure of public control that Express its essence. This is the way to consider individual citizens and their entities (as subjects) and public-law power structures (objects). Within this approach, the author defines public control as a set of social processes that are carried out to monitor the functioning of public legal entities and their individual structures (state authorities), check their activities for compliance with accepted social norms and public expectations, and also to apply certain measures of influence to these structures in order to level possible deviations from these constants.

The perspective of the research is the analysis of the practical implementation of social processes that determine the essence of public control in real conditions of a specific historical situation.

Key words: public control; social science; democratic rule of law; public opinion; bilateral interaction; state power.

Введение. Современный этап развития человеческой цивилизации характеризуется формированием устойчивого стандарта общественно-политического развития, связанного с существованием правовой демократической государственности. Именно такая форма государства рассматривается в качестве ключевого фактора обеспечения прогрессивного развития человеческого общества в условиях соблюдения конструктивного баланса частных и публичных интересов при безусловном приоритете первых.

Научное обоснование данного общественно-политического концепта предполагает всестороннее исследование общественных отношений, обусловленных двусторонним взаимодействием властных структур и общества. В настоящее время данный вопрос рассматривается в качестве одного из важнейших предметов исследования общественных наук, в первую очередь, политологии и социологии. В рамках последней повышается значение исследования феномена общественного контроля, который рассматривается как механизм воздействия на власть со стороны общества, а следовательно, в качестве ведущей предпосылки существования правовой демократической государственности.
Методологические подходы к исследованию сущности общественного контроля. На наш взгляд, понятие «общественный контроль» необходимо рассматривать в качестве базовой категории социологической науки. Вместе с тем длительный период времени, вплоть до конца 1980-х гг., в рамках социологического дискурса это понятие анализировалось в ином контексте.

При этом в качестве ключевых предпосылок научной разработки общественного контроля следует выделять, во-первых, исследование «отклонений» социального поведения конкретной личности, а во-вторых, исследование крупных социальных конфликтов, имеющих политический характер.

В первом случае социальный контроль рассматривался в качестве практически реализуемой совокупности санкций, обеспечивающих недопущение со стороны конкретного субъекта общественных отношений нарушений установленной системы социального нормирования. Именно в таком контексте социальный контроль исследовал один из классиков социологической науки Г. Тард. Исследователь рассматривал социальный контроль в качестве механизма ресоциализации лиц, осуществляющих девиантное (антиобщественное) поведение. Иными словами, Г. Тард 
обосновывал сущность социального контроля в сравнительно узком понимании - лишь в контексте профилактики преступного поведения личности [6]. Тард актуализировал дальнейшую разработку данного понятия в западной социологии в контексте таких социальных феноменов, как социальная солидарность, общественное мнение, социальные нормы (в том числе и нормы действующего законодательства) в качестве механизма социализации личности и обеспечения профилактики девиаций в обществе.

Учитывая предмет настоящей работы, более актуальным представляется второй из вышеуказанных подходов к восприятию понятия «общественный контроль» в рамках социологического дискурса, представители которого анализировали его в качестве одной из базовых категорий конфликтологии, объясняющей детерминацию социальных конфликтов. В этой связи следует отметить работы Л.И. Петражицкого, Г.Д. Гурвича, Р. Паунда, Г. Шельски.

Закрепление статуса формы правового демократического государства в качестве единственной альтернативы, обеспечивающей поступательное развитие общества, что стало следствием окончания концептуального противостояния капиталистической и социалистической систем в рамках «холодной войны», обусловило начало исследования общественного контроля в новом контексте. В этой связи в рамках зарубежного, а позднее и отечественного социологического дискурса стали появляться исследования, содержащие «пограничные», универсальные интерпретации сущности социального контроля, претендующие на объяснение его практического значения в контексте вовлечения больших социальных групп в политическую сферу общественных отношений. Иными словами, в рамках социологического дискурса стала происходить «политизация» интерпретации общественного контроля.

Фундаментальная база для социологического анализа общественного контроля в вышеуказанном контексте была заложена классиками зарубежной философии, в первую очередь, философами эпохи Просвещения и представителями немецкой классической философии. В частности, такие мыслители, как П. Гольбах, Ж.-Ж. Руссо,
И. Кант, Г. Гегель обосновывали значимость воздействия общества на власть с целью недопущения установления деспотического правления в рамках тоталитарного режима, нивелирующего естественные права и свободы человека, а следовательно, антигуманного по своей сути.

Эти идеи были восприняты уже в рамках периода развития советской социологической науки. В этой связи обращают на себя внимание исследования В.А. Климова, К.Е. Игошева, А. М. Яковлева и С. М. Боботова.

В исследованиях В. А. Климова и К. Е. Игошева было сформулировано общее представление о сущности общественного контроля, рассматриваемого в политическом контексте.

К.Е. Игошев рассматривал общественный (социальный) контроль в качестве исторически сложившегося сложноорганизованного механизма воздействия на тот или иной социальный субъект с целью обеспечения его направленной деятельности, реализуемой в рамках принятых в обществе систем социальных норм и ценностей, отражающих интересы большинства его членов. Таким образом, общественный (социальный) контроль понимался ученым в качестве специфической формы управления деятельностью социальных институтов, способа саморегуляции жизни социального организма, обеспечивающих функционирование всех его элементов в рамках определенной урегулированности и порядка.

При этом Игошев выделял два самостоятельных контекста данного понятия. В широком смысле социальный контроль удовлетворяет социальную потребность в обеспечении регулирования деятельности крупных социальных субъектов и общественных институтов на основе предъявляемых объективных требований и правил. При этом посредством организации и осуществления социального контроля достигается закрепление, охрана и развитие общественных отношений, а также обеспечивается определенная направленность всей деятельности наиболее значимых акторов общественных отношений.

В узком смысле социальный контроль, по Игошеву, представляет собой совокупность средств государственного и общественного воздействия на конкретную личность с целью стимуляции осуществления обще- 
ственно-полезной деятельности и исключения общественно-опасного поведения. Другими словами, в узком смысле социальный контроль, по мнению ученого, реализуется в виде постоянного динамического воздействия государственных структур и общественных институтов на духовный мир личности (непосредственного объекта, адресата воздействия), в результате которого получают свою практическую реализацию общественные интересы, а также требования нормативного и ненормативного характера [3].

По мнению В.А. Климова, общественный контроль необходимо представлять в качестве совокупности общественных процессов, реализуемых для организации наблюдения за функционированием социальных объектов (социальных общностей, социальных институтов, индивидов), проверки и оценки результатов их деятельности в соответствии с социальными нормами, управленческими решениями, а также применения к объектам определенных мер воздействия с целью ликвидации негативных явлений (социальных отклонений) и всестороннего развития позитивных явлений и тенденций [4].

В представлении А.М. Яковлева социальный контроль следует рассматривать в качестве процесса взаимодействия отдельных индивидов и различных социальных структур - социальных групп, классов, общностей, институтов. Соответственно, сущность данного процесса образуют два вида действий - индивидуальное и коллективное, иначе говоря, контролируемая деятельность индивидов и контролирующая деятельность социальных образований. В первом случае объектом управления (контроля) является индивид, которому не предоставлено право выбора социально значимого действия, во втором объектом контроля может выступать социально-значимая деятельность, реализуемая государством посредством элементов своего аппарата (органов власти) [9].

С. В. Боботов обосновал теорию институционализации социального контроля, в соответствии с которой данный феномен находит свое практическое выражение в деятельности системы учреждений и агентов, непосредственно относящихся к государственному аппарату либо представляющих структуры гражданского общества. Кроме того, в качес- тве самостоятельных субъектов общественного контроля необходимо рассматривать институт семьи, малые контактные группы, peферентные группы, замкнутые корпорации, а также лидеров и авторитетных личностей.

Таким образом, следует еще раз подчеркнуть тот факт, что значимые предпосылки для социологического осмысления понятия «общественный контроль» в качестве механизма воздействия на власть со стороны общественных структур сформировались еще в рамках советского периода развития социологии.

Понимание общественного контроля в рамках современного социологического дискурса. Анализ современного состояния социологического дискурса позволяет сделать вывод о существенных различиях в понимании сущности общественного контроля в зарубежных и отечественных исследованиях.

В рамках зарубежной социологической науки к настоящему времени разработан достаточно четкий категориальный аппарат, в рамках которого отдельные категории отражают специфику реализации социального контроля. Так, «public control» используется для обозначения управленческого воздействия разнообразных структур гражданского общества на деятельность публично-правовых образований - органов государственной власти. Категория «social control» рассматривается в традиционном социологическом смысле - в качестве системы санкций, позволяющих обеспечивать позитивное социальное поведение индивидов, непротиворечащее общественным интересам. Гражданский контроль над вооруженными силами, подчинение военных гражданским властям рассматривается как «civilian control». В качестве общего понятия, отражающего активность граждан в принятии управленческих решений, используется термин «civic engagement» («гражданское участие») [2].

Специфика современного социологического дискурса анализа понятия «общественный контроль» в рамках отечественной социологии, по нашему мнению, определяется двумя обстоятельствами: во-первых, сущностным разделением категорий «социальный контроль» и «общественный 
контроль», а во-вторых, их дифференциацией по значимости в контексте родового и видового понятия.

Характеризуя первый из указанных аспектов, А.И. Лапшина справедливо отмечает, что «в научной литературе под социальным контролем чаще всего понимают деятельность по обеспечению соответствия поведения членов общества, отдельных субъектов управления, социальных групп социальным нормам и ценностям, которые определяют меры должного, ожидаемого поведения указанных субъектов. Его задачей является сведение к минимуму расхождений между системой ожиданий и требований, предъявляемых обществом к поведению его членов, и их фактической деятельностью, приведение общества к «равновесному состоянию». В свою очередь общественный контроль за деятельностью органов государственной власти также основан на необходимости обеспечения соблюдения социальных норм и ценностей, ожиданий общества. При этом он направлен на приведение в соответствие с нормативной системой фактической деятельности государственного аппарата и осуществляется такими субъектами, как непосредственно граждане, их объединения, негосударственные организации и другие институты гражданского общества» [5, с. 138-139].

Характерным примером второй из указанных исследовательских тенденций является определение социального контроля в качестве «особой социальной практики, обеспечивающей эффективную саморегуляцию социальных систем, выполнение ими важнейшей функции поддержки устойчивого существования, развития и воспроизводства социума на любых уровнях его организации» [8, с. 8]. Кроме того, отечественные социологи - представители неоинституционального подхода (М. Позднякова, Л. Рыбакова, Т. Хугаров) рассматривают социальный контроль в качестве социального механизма, функционирование которого определяется формальными и культурными нормами. Ученые допускают влияние социального контроля на нормы в качестве ответной реакции, требующей их корректировки в рамках заданной социетальной системы координат. Соответственно, по аналогии с нормами исследователи выделяют два вида контроля - правовой и общественный, что подчеркивает его производность и «обслуживающую» функцию. Подобный подход предписывает социальному контролю выполнение посреднически-регламентирующей функции между нормами и поведением социальных акторов [7, с. 140]. Указанные трактовки понятия «социальный контроль» позволяют рассматривать его в качестве родового по отношению к видовым - общественному и государственному.

Заключение. Проведенный анализ показывает, что в рамках современного российского социологического дискурса социальный контроль исследуется в рамках различных исследовательских подходов: институционального (в качестве социального механизма, обеспечивающего устойчивость общества на основе формальных и неформальных норм), структурно-функционального (в качестве механизма нивелирования девиантного поведения), системного (в качестве механизма управленческого воздействия, peализуемого с целью формирования у субъектов модели желаемого поведения). При этом в качестве ключевого тренда социологического исследования общественного контроля следует рассматривать выявление новых субъектно-объектных связей, выражающих его сущность. В таком качестве рассматриваются отдельные граждане и их образования (в качестве субъектов) и публично-правовые властные структуры (объекты).

С учетом данной тенденции общественный контроль следует определять как совокупность общественных процессов, осуществляемых с целью наблюдения за функционированием публично-правовых образований и их отдельных структур (органов государственной власти), проверки их деятельности на предмет соответствия принятым социальным нормам, общественным ожиданиям, а также с целью применения к указанным структурам определенных мер воздействия для нивелирования возможных отклонений от указанных констант.

\section{Литература}

1. Боботов С.В. Буржуазная социология права. - М.: Юридическая. лит., 1978. - 222 с. 
2. Грошева И.А., Костин В.А. Гражданский контроль в современной России как предмет социологического исследования [Электронный ресурс]. - Режим доступа: https://cyberleninka.ru/article/n/grazhdanskiykontrol-v-sovremennoy-rossii-kak-predmetsotsiologicheskogo-issledovaniya (Дата обращения: 10.09.2020).

3. Игошев K.E. Социальный контроль и профилактика преступлений. - Горький: высшая школа МВД, 1976. - 91 с.

4. Климов В.А. Социальный контроль в развитом социалистическом обществе. Саратов: изд-во Сарат. ун-та, 1984. — 99 с.

5. Лапшина А.И. Общественный контроль и иные институты контроля общества за деятельностью органов государственной власти // Правовое государство: теория и практика. — №2. - 2014. — С. 136-140.

6. Тард Г. Монадология и социология. Пермь: Гиле Пресс, 2016. - 119 с.

7. Осяк А.Н., Пестов Р.А., Шаповалова Т.Н., Чернобровкина Н.И. Социальный контроль как предмет научной рефлексии // Философия права. - №3. - 2017. - С. 137-143.

8. Поверинов И. Е., Писачкин Д. В. Социальный контроль в системе социологического знания // Гуманитарий: актуальные проблемы гуманитарной науки и образования. №2. - 2013. - С. 73-82.

9. Яковлев А. М. Социальный контроль в изменяющемся мире (нормативно-психологический аспект) / В сб.: Социология и проблемы социального развития. - М.: Наука, 1977. - C. 33-42.

\section{References}

1. Bobotov S. V. Burzhuaznaja sociologija prava [Bourgeois sociology of law]. - Moscow: Juridicheskaja. lit., 1978. - $222 \mathrm{p}$.

2. Grosheva I.A., Kostin V.A. Grazhdanskij kontrol' v sovremennoj Rossii kak predmet socio- logicheskogo issledovanija [Civil control in modern Russia as a subject of sociological research] [Jelektronnyj resurs]. — URL: https://cyberleninka.ru/article/n/grazhdanskiy-kontrol-v-sovremennoy-rossii-kak-predmet-sotsiologicheskogo-issledovaniya (Date accessed: 10.09.2020).

3. Igoshev K.E. Social'nyj kontrol' i profilaktika prestuplenij [Social control and prevention of crimes]. - Gorky: vysshaja shkola MVD, 1976. - $91 \mathrm{p}$.

4. Klimov V.A. Social'nyj kontrol' v razvitom socialisticheskom obshhestve [Social control in a developed socialist society]. - Saratov: izd-vo Sarat. un-ta, 1984. - 99 p.

5.Lapshina A.I. Obshhestvennyj kontrol'i inye instituty kontrolja obshhestva za dejatel'nost'ju organov gosudarstvennoj vlasti [Public control and other institutions of control of society over the activities of state authorities]// Pravovoe gosudarstvo: teorija i praktika [Legal state: theory and practice]. — №2. - 2014. - Pp. 136-140.

6. Tard G. Monadologija i sociologija [Monadology and sociology]. - Perm': Gile Press, 2016. - $119 \mathrm{p}$.

7. Osjak A.N., Pestov R.A., Shapovalova T.N., Chernobrovkina N.I. Social'nyj kontrol' kak predmet nauchnoj refleksii [Social control as a subject of scientific reflection] // Filosofija prava [Philosophy of law]. - №3. - 2017. - Pp. 137-143.

8. Poverinov I. E., Pisachkin D. V. Social'nyj kontrol' v sisteme sociologicheskogo znanija [Social control in the system of sociological knowledge] // Gumanitarij: aktual'nye problemy gumanitarnoj nauki i obrazovanija [Humanities: actual problems of Humanities and education]. — №2. - 2013. - Pp. 73-82.

9. Jakovlev A.M. Social'nyj kontrol' v izmenjajushhemsja mire (normativno-psihologicheskij aspekt) [Social control in the changing world (normative and psychological aspect)] / V sb.: Sociologija i problemy social'nogo razvitija [In: Sociology and problems of social development]. - Moscow: Nauka, 1977. - Pp. 33-42. 


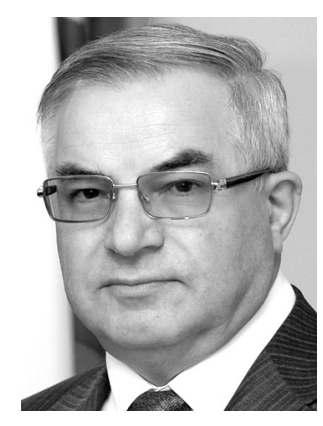

Кривопусков Виктор Владимирович - доктор социологических наук, советник Генерального директора АO «Главкосмос», видный общественный деятель, председатель Российского общества дружбы и сотрудничества с Арменией, член Генерального Совета и руководитель Комитета «Космос - пространство мира, доверия и сотрудничества» Ассамблеи народов Евразии.

Krivopuskov Viktor Vladimirovich - Doctor of Sociological Sciences, Adviser to the General Director of Glavkosmos JSC, prominent public figure, Chairman of the Russian society for friendship and cooperation with Armenia, member of the General Council and head of the Committee «Space - space of peace, trust and cooperation» of the Assembly of Peoples of Eurasia.

129110, г. Москва, ул. Гиляровского, 39, стр. 3

39 Gilyarovskogo st., bld. 3, 129110, Moscow, Russia

E-mail: rossotram@gmail.com

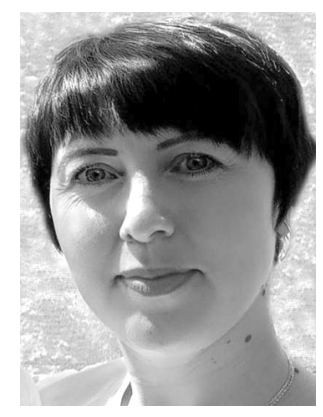

Первякова Раиса Николаевна - соискатель кафедры «Теоретическая социология и методология региональных исследований» Института социологии и регионоведения Южного федерального университета.

Pervyakova Raisa Nickolaevna - applicant of the Department «Theoretical Sociology and Methodology of Regional Studies», Institute of Sociology and Regional Studies, Southern Federal University.

344006, г. Ростов-на-Дону, ул. Пушкинская, 160 160 Pushkinskaya st., 344006, Rostov-on-Don, Russia

E-mail: pervya.com@mail.ru 